University of Wollongong

Research Online

Faculty of Social Sciences - Papers (Archive) Faculty of Arts, Social Sciences \& Humanities

2013

Challenges to getting evidence into practice: Expert clinician perspectives on psychotherapy for personality disorders

Kye L. McCarthy

University of Wollongong, klm825@uowmail.edu.au

Phoebe E. Carter

University of Wollongong, pcarter@uow.edu.au

Brin F. S Grenyer

University of Wollongong, grenyer@uow.edu.au

Follow this and additional works at: https://ro.uow.edu.au/sspapers

Part of the Education Commons, and the Social and Behavioral Sciences Commons

Research Online is the open access institutional repository for the University of Wollongong. For further information contact the UOW Library: research-pubs@uow.edu.au 


\title{
Challenges to getting evidence into practice: Expert clinician perspectives on psychotherapy for personality disorders
}

\author{
Abstract \\ Background No known recent studies have investigated service provision for personality disorder in \\ Australia, despite international studies suggesting provision of such services is sub-optimal. Aims This \\ study aimed to gain insight into psychotherapy provided for personality disorders, treatments considered \\ optimal by clinicians and opinions of clinicians on the current levels of care. Methods The views of 60 \\ experienced clinicians working with personality disorders were sampled. Results Data showed significant \\ gaps between current practices for the treatment of personality disorders provided by clinicians \\ compared to their perceptions of optimal treatment practice. Conclusions This study highlights the \\ evidence-practice gap and the need for more training for clinicians in the treatment of personality \\ disorders and service improvements to implement optimal care strategies.
}

\section{Keywords}

practice, getting, expert, clinician, perspectives, psychotherapy, personality, disorders, evidence, into, challenges

\section{Disciplines}

Education | Social and Behavioral Sciences

\section{Publication Details}

McCarthy, K. L., Carter, P. E. \& Grenyer, B. F. S. (2013). Challenges to getting evidence into practice: Expert clinician perspectives on psychotherapy for personality disorders. Journal Of Mental Health, 22 (6), 482-491. 
Word count: 3993

Tables: 3

McCarthy, K.L., Carter, P.E., Grenyer, B.F.S. (2013) Challenges to getting evidence into practice: Expert clinician perspectives on psychotherapy for personality disorders. Journal of Mental Health, 22 (6), 482-491. DOI: 10.3109/09638237.2013.779367. Revision submitted 18/12/2012

Challenges to getting evidence into practice: Expert clinician perspectives on psychotherapy for personality disorders

Short title: Challenges to getting evidence into practice

Research Article

Authors: Kye L. McCarthy, Phoebe E. Carter \& *Brin F. S. Grenyer.

Illawarra Health and Medical Research Institute \& University of Wollongong

*Corresponding Author:

Professor Brin Grenyer,

School of Psychology and Illawarra Health \& Medical Research Institute

University of Wollongong,

NSW Australia, 2522

Ph: +61 242213474

Fax: +612 42218130

Email: grenyer@uow.edu.au 
Title: Challenges to getting evidence into practice: Expert clinician perspectives on psychotherapy for personality disorders

\begin{abstract}
Background: No known recent studies have investigated service provision for personality disorder in Australia, despite international studies suggesting provision of such services is sub-optimal.
\end{abstract}

Aims: This study aimed to gain insight into psychotherapy provided for personality disorders, treatments considered optimal by clinicians, and opinions of clinicians on the current levels of care.

Methods: The views of 60 experienced clinicians working with personality disorders were sampled.

Results: Data showed significant gaps between current practices for the treatment of personality disorders provided by clinicians compared to their perceptions of optimal treatment practice.

Conclusions: This study highlights the evidence-practice gap and the need for more training for clinicians in the treatment of personality disorders and service improvements to implement optimal care strategies.

Declaration of Interests: Nil

Key Words: Personality disorders; psychotherapy; evidence-based practice; treatment guidelines 
Personality disorders are highly prevalent in mental health services and are associated with substantial morbidity, functional impairment, and suicidality (Lieb et al., 2004). Personality disorders are marked by chronic patterns of self-defeating behaviours, and an inability to maintain interpersonal relationships (Carter \& Grenyer, 2012). The goal to lead functional, socially connected lives is often out of reach without treatment (Grenyer, 2007). Of the personality disorder subtypes, borderline is the most common in mental health services, estimated to be present in $22.6 \%$ of psychiatric outpatients, with a greater lifetime utilisation of medications and psychotherapy (Korzekwa et al., 2008). Borderline personality disorder is also the most widely researched personality disorder (NICE, 2009).

The National Institute for Clinical Excellence (NICE; 2009) has published treatment guidelines for antisocial and borderline personality disorders in the United Kingdom, based upon expert and service user opinions and systematic review of effectiveness of interventions (Harding et al., 2010). Further, the American Psychiatric Association (APA; 2001) practice guidelines for the treatment of borderline personality disorder continue to be used to inform good clinical practice (McMain et al., 2009).

NICE guidelines suggest that Cognitive Behaviour Therapy be employed for the treatment of antisocial personality disorder, however, evidence for psychological treatment of this disorder is sparse (Gibbon et al., 2010; NICE, 2009). Evidence for specific psychological treatments for other personality disorders is further limited, with no current clinical guidelines or systematic reviews. However, evidence shows that a range of psychotherapies are effective in attenuating borderline psychopathology, including Dialectical Behaviour Therapy (DBT; Leichsenring et al., 2011; Stoffers et al., 2012); schema-focused therapy and transference-focused dynamic psychotherapy (Zanarini, 2009); and mentalization-based treatment (Bateman \& Fonagy, 2009). However, literature suggests there is a gap between evidence and practice in treatment settings (Gotham, 2006). 
People in Australia with personality disorder most commonly engage in outpatient treatment in community mental health facilities, with some States having specialised personality disorder services. However, Australian treatment guidelines for personality disorders are old (The Quality Assurance Project, 1990; 1991a; 1991b) and the Australian Psychological Society (APS; 2010) review of empirically-based treatments only reviews selected literature. There have not been any recent Australian treatment guidelines published, although these are currently being developed by the Australian National Health and Medical Research Council and also the Project Air Strategy for Personality Disorders (2010). Often in the development of such guidelines, views of experienced clinicians are sought as a first stage in developing good treatment practices, along with up-to-date empirical studies of treatment efficacy (e.g. NICE, 2009).

Another study has examined such views from clinicians. Ogrodniczuk, Kealy and Howell-Jones (2009) surveyed Canadian clinicians about treatments they provided, and their perspectives on the optimal treatments for borderline personality disorder. Ogrodniczuk et al. (2009) found discrepancies between treatment characteristics provided and characteristics clinicians believed to be optimal. High numbers of the clinicians stated that they provided case or crisis management for borderline personality disorder patients, yet low numbers of clinicians believed these treatments were optimal. Whilst the majority of the Canadian clinicians indicated that they believed DBT to be the optimal treatment for borderline personality disorder, clinicians showed a relatively low awareness of other empiricallysupported therapies (Ogrodniczuk et al., 2009).

The present study aims to gain further insight into the relationship between clinician practices and opinions, to examine the reach of research into practice within a group of experienced Australian clinicians. Such data can assist in monitoring the uptake of evidence- 
based practices, as well the opinions of clinicians in the field, in developing treatment recommendations.

\section{Method}

\section{Participants}

Participants were 60 experienced clinicians who attended the fourth annual Treatment of Personality Disorder Conference held in the State of New South Wales, Australia. The clinicians who attend this conference are specifically invited because they are experienced senior clinicians and psychotherapists involved in the major treatment programs for personality disorder within the State. Most have had advanced postgraduate training at a doctoral level in personality disorders, and many have also undertaken intensive training in one of the major approaches to personality disorder treatment (e.g. DBT, MBT, Schema, TFP, etc). Table 1 outlines sample characteristics.

\section{TABLE1 HERE}

\section{Procedure}

Clinicians answered 12-items regarding their demographics (Table 1). They then completed a 12-item questionnaire (Table 2 and 3) derived from the items used by Ogrodniczuk et al. (2009). Ethics approval was obtained from the Institutional Review Board and clinicians consented to participating in the research.

The survey consisted of questions regarding type, format and duration of treatments clinicians provided for personality disorders, and their opinion as to the most optimal treatment type, format and duration. The survey also asked for clinicians' opinions about current availabilities of treatments for personality disorders, and their personal confidence 
level in treating personality disorders. Items used were fixed responses, with yes/no, rating scales and forced-choice options. The option was also given to describe treatments provided that were not listed.

\section{Statistical Analyses}

Frequencies and proportions were calculated for respondents in each category. The significance of differences between provided and optimal treatment options were calculated using z-ratios and probabilities for the difference between independent proportions.

Results

\section{TABLE2 HERE}

\section{Treatment provided by clinicians}

The majority of the Australian sample of clinicians studied here provide DBT at their service (86.7\%), but over half of the clinicians also provide crisis management (65\%), case management (55\%), CBT (58.3\%) and supportive psychotherapy (58.4\%) as treatments for personality disorders. Clinicians did not consistently indicate that they commonly provided any treatments other than the ones listed in the survey. Clinicians most commonly provide a combined individual and group treatment format (63.3\%). Few clinicians provide group treatment only (3.3\%). Clinicians most commonly indicated that they provide long-term treatment lengths of more than 40 sessions (43.3\%), closely followed by varied treatment lengths dependent on client/presentation (38.3\%). Fewest clinicians (5\%) provide brief treatments of 1-10 sessions. 
Opinions of clinicians regarding optimal treatment

Over half of the clinicians indicated they believe DBT to be the optimal treatment for personality disorders (64.7\%). The next largest group believed psychodynamic therapy to be the optimal (17.6\%), with no one indicating CBT to be optimal. The vast majority of clinicians identified a combined individual and group format as the optimal treatment format (90.9\%), with no one endorsing group-only treatment formats as optimal. Over half of clinicians believe that long-term treatment is optimal (62.1\%), with the next largest group believing that treatment length should vary depending on client/presentation (31\%). No one identified brief treatments of 1-10 sessions to be optimal.

Clinicians' perceptions of current level of care

About half of the Australian sample of clinicians perceive availability of treatment in New South Wales to be fair (55.2\%), but a large group also perceived availability to be poor (37.9\%). Clinicians most commonly believed that lack of resources is the most significant barrier to treatment within NSW (51\%). 25.5\% believed stigma regarding personality disorders is the most significant barrier. Clinicians most commonly rated themselves as 'quite confident' in treating people with personality disorders (42.1\%). 38.6\% rated themselves as 'somewhat confident'. The vast majority of the clinicians indicated that treatment of people with personality disorders should be a high priority within the health system (96.7\%); felt there is a need for more training on the treatment of personality disorders (98.3\%); and, were willing to participate in training (98.2\%).

\section{TABLE3 HERE}

Treatment provided by services versus clinicians’ opinions of optimal treatment 
For a number of treatments, significantly more clinicians provide treatments that they believe to be less optimal. Specifically, significantly more clinicians provide CBT to treat personality disorders (58.3\%) with no one believing this to be optimal (0\%); and significantly more clinicians provide supportive psychotherapy (58.4\%) with only 3.9\% indicating this as the most optimal treatment. Further, significantly more clinicians provide crisis management (65\%) compared to those who indicate this to be optimal (5.9\%); more clinicians provide case management (55\%) compared to those who indicate this to be optimal treatment $(7.8 \%)$; and more clinicians provide DBT (86.7\%) than those who think it is the optimal treatment (64.7\%).

Close to $90 \%$ of the clinicians felt that combined individual and group therapy was the most optimal treatment format. However, only just over half actually provided combined treatment. Similarly, two-thirds believed long-term treatment is optimal despite less than half being able to provide therapy longer than 40 sessions.

\section{Cross-Study Comparison}

Whilst some differences between the samples and methodologies of the present study and that of Ogrodniczuk et al. (2009) are recognised (face-to-face targeted survey versus general mail-out), out of interest we compared the results of the Canadian and Australian samples of clinicians. It was found that of treatment provided, significantly more of the Australian sample of clinicians provided crisis management $(18.4 \%, N=212, n=39)$, than did the Canadian sample of clinicians $(8.6 \%, N=81, n=7), z=2.05, p=.040$. Significantly more of the Canadian clinicians provided an individual treatment format $(60 \%, N=80, n=48)$, than did the Australian sample of clinicians (33.3\%, $N=60, n=20), z=-3.12, p=.002$, whereas more of the Australian clinicians provided a combined individual and group format $(63.3 \%, \mathrm{~N}=60$, $\mathrm{n}=38$ ) than did the Canadian clinicians $(28.8 \%, \mathrm{~N}=80, \mathrm{n}=23) \mathrm{z}=2.74, \mathrm{p}=.006$. Significantly 
more of the Australian sample of clinicians varied treatment length based on client presentation (38.3\%, $N=60, n=23$ ) than did the Canadian sample (14.1\%, $N=71, n=10)$, $\mathrm{z}=3.19, \mathrm{p}=.001$. In terms of clinicians' opinions regarding optimal treatment, significantly more of the Australian sample of clinicians thought that DBT was the most optimal treatment (64.7\%, $\mathrm{N}=51, \mathrm{n}=33$ ) than did the Canadian clinicians (45.3\%, $N=106, \mathrm{n}=48$ ), $\mathrm{z}=2.28$, $\mathrm{p}=.023$, whereas more of the Canadian clinicians reported CBT to be the optimal treatment (11.3\%, N=106, $\mathrm{n}=12)$ than did the Australian clinicians $(0 \%, \mathrm{~N}=51, \mathrm{n}=0) \mathrm{z}=-2.50, \mathrm{p}=.012$. In terms of optimal treatment format, significantly more of the Australian clinicians thought that a combined group and individual format was optimal (90.9\%, $N=55, n=50)$, than did the Canadian clinicians $(47.7 \%, \mathrm{~N}=86, \mathrm{n}=41), \mathrm{z}=5.23, \mathrm{p}=.000$, whereas more of the Canadian clinicians felt that group treatments alone were optimal $(27.9 \%, N=86, n=24)$, than did the Australian clinicians $(0 \%, \mathrm{~N}=55, \mathrm{n}=0), \mathrm{z}=-4.30, \mathrm{p}=.000$. Australian clinicians were clearer in their view that long-term treatments were optimal $(62.1 \%, \mathrm{~N}=58, \mathrm{n}=36)$ compared to the Canadian sample (42.4\%, $\mathrm{N}=99, \mathrm{n}=42), \mathrm{z}=2.38, \mathrm{p}=.018$.

\section{Discussion}

This study aimed to gain insight into treatments provided for personality disorders by experienced Australian clinicians, and to compare this to treatments they consider to be optimal. There were discrepancies found between treatment characteristics clinicians provide for personality disorders within their services, and treatment characteristics they believe to be optimal, suggesting a gap between evidence-based treatments, practice within services, and clinician beliefs about best practice.

Most clinicians provide DBT, a combined individual and group therapy format, and long-term treatment for personality disorder. However, it appears that more clinicians provide CBT, supportive psychotherapy, crisis and case management, and DBT, than who actually 
believe these treatments to be optimal. Notable proportions of clinicians provide individual therapy alone, despite a significantly lower proportion believing it optimal. The results suggest that treatments provided by clinicians are more diverse than those deemed optimal. It should be noted that although clinicians responded to the survey in terms of all personality disorders they work with, the evidence base for treatments for personality disorders other than borderline personality disorder is limited. However, research also suggests that the majority of clients presenting to health services have a borderline diagnosis (Korzekwa et al., 2008). Thus it seems that these clinicians may be aware of only some of the effective treatments for personality disorders. Despite the weight of evidence supporting DBT, in that it has the largest number of trials and therefore has a clearer evidence basis (NICE, 2009), there was less awareness of evidence for the range of emerging approaches such as psychodynamic and schema-based treatments. This may reflect the lack of training and education opportunities in evidence-based therapies, or sanctioned preferences by training programs. Considering the results indicated that $51 \%$ of clinicians felt that lack of resources significantly impacted treatment, it is also likely that service structure and resources impacted on the ability of clinicians to implement a range of evidence-based treatments. The preference of the Australian clinicians for long-term treatments is consistent with the NICE (2009) clinical guidelines for the treatment of borderline personality disorder, and the preference for combined individual and group treatment is also consistent with the APA (2001) treatment guidelines. The vast majority of clinicians felt there was a need for further training on the treatment of personality disorders, and indicated willingness to participate in this.

There were a number of discrepancies found between the current Australian sample of clinicians and the previous Canadian sample of Ogrodniczuk et al., (2009). The Australian sample of clinicians most commonly provide DBT, whilst the Canadian sample of clinicians most commonly provide case management. More Canadian clinicians provided individual 
treatment, whilst more Australian clinicians provided combined treatment. Both Australian and Canadian samples of clinicians most commonly felt that DBT is the most optimal treatment, and that combined group and individual, long-term treatments are optimal.

Methodological and sample differences between these studies may in part contribute to these discrepancies. In the current study, it should be noted that participants completed the questionnaire in a face-to-face setting, and were a specific sample interested and experienced in working with personality disorders and thus had interest in attending the conference. Ogrodniczuk et al. (2009) sent the questionnaire via email to all clinicians working in community mental health centres and outpatient clinics in the largest health authority in British Columbia, with a 43\% response rate. It would be expected, however, that those who responded to the Canadian survey were more interested and involved in personality disorder treatment. Despite the differences in recruitment strategy, it should be noted that the profile of clinicians sampled was highly similar, with the Australian sample predominantly working in community mental health facilities and outpatient clinics (88.3\%) which was the source of the Canadian sample. Both samples appeared to have similar exposure to personality disorder clients in their case-loads. Despite this, variations between Australian and Canadian sample recuitment may account for some differences in the results found by the current study in comparison to Ogrodniczuk et al. (2009).

Interestingly, similar results have been found in studies of service use in other countries. Price et al. (2009) investigated the opinions of service providers, users, carers and commissioners in 11 new community-based services in English regions. Crawford et al. (2007) investigated the service delivery and organisation of 11 pilot community mental health services for personality disorder in England. These studies found that participants believed treatment should be long-term, and that service providers need to remain informed about personality disorder and treatment. 
This study highlights a significant gap between current practices and perceptions of optimal practice, particularly for borderline personality disorder and particularly in the provision of longer-term structured therapies in comparison to crisis services and unspecified case management. It further highlights a gap in research on treatments for personality disorders other than borderline personality disorder. This research indicates a need for current treatment guidelines for clinicians to utilise in treatment of personality disorder, as well as continued training to ensure clinicians have current knowledge. Services also need to be equipped to support implementation of up-to-date evidence-based treatments. Future research may seek to further monitor these trends across different countries and services, to foster understanding of the impact of research on provision of optimal treatments for personality disorders. 


\section{References}

American Psychiatric Association Practice Guidelines (2001). Practice guideline for the treatment of patients with borderline personality disorder. American Journal of Psychiatry, 158, 1-52.

Australian Psychological Society (2010). Evidence-based Psychological Interventions in the Treatment of Mental Disorders: A Literature Review ( $3^{\text {rd }}$ ed.). Retrieved from http://www.psychology.org.au/Assets/Files/Evidence-Based-PsychologicalInterventions.pdf

Bateman, A., \& Fonagy, P. (2009).Randomized controlled trial of outpatient mentalizationbased treatment versus structured clinical management for borderline personality disorder. American Journal of Psychiatry, 166, 1355-1364.

Carter, P.E., \& Grenyer, B.F.S. (2012). Expressive language disturbance in Borderline Personality Disorder in response to emotional autobiographical stimuli. Journal of Personality Disorders. e-View Ahead of Print.

Crawford, M., Rutter, D., Price, K., Weaver, T., Josson, M., Tyrer, P., ... Moran, P. (2007). Learning the lessons: A multimethod evaluation of dedicated community-based services for people with personality disorder. London: National Co-ordinating Centre for NHS Service Delivery and Organization. Retrieved from http://www.netscc.ac.uk/hsdr/files/project/SDO_FR_08-1404-083_V01.pdf

Gibbon, S., Duggan, C., Stoffers, J., Huband, N., Völlm, B. A., Ferriter, M., \& Lieb, K. (2010). Psychological interventions for antisocial personality disorder. Cochrane Database of Systematic Reviews, 6(CD007668).

Gotham, H. J. (2006). Advancing the implementation of evidence-based practices into clinical practice: How do we get there from here? Professional Psychology: Research and Practice, 37, 606-613. 
Grenyer, B.F.S. (2007). Hope for sustaining a positive three-year therapeutic relationship with borderline patients. Archives of General Psychiatry, 64, 609.

Harding, E., Brown, D., Hayward, M., \& Pettinari, C. (2010). Service user perceptions of involvement in developing mental health guideline: A grounded theory study. Journal of Mental Health, 19, 249-257.

Korzekwa, M. I., Dell, P. F., Links, P. S., Thabane, L., \& Webb, S. P. (2008). Estimating the prevalence of borderline personality disorder in psychiatric outpatients using a twophase procedure. Comprehensive Psychiatry, 49, 380-386.

Leichsenring, F., Leibing, E., Kruse, J., New, A. S., \& Leweke, F. (2011). Borderline personality disorder. Lancet, 377, 74-84.

Lieb, K., Zanarini, M. C., Schmahl, C., Linehan, M. M., \& Bohus, M. (2004). Borderline personality disorder. Lancet, 364, 453-461.

McMain, S. F., Links, P. S., Gnam, W. H., Guimond,T., Cardish, R. J., Korman, L., \& Streiner, D. L. (2009). A randomized trial of dialectical behavior therapy versus general psychiatric management for borderline personality disorder. American Journal of Psychiatry, 166, 1365-1374.

National Institute for Health and Clinical Excellence (2009). Borderline Personality Disorder: Treatment and Management. London: National Institute for Health and Clinical Excellence. Retrieved from http://www.nice.org.uk/nicemedia/pdf/CG78NICEGuideline.pdf

Ogrodniczuk, J. S., Kealy, D., \& Howell-Jones, G. (2009). A view from the trenches: A survey of Canadian clinicians’ perspectives regarding the treatment of borderline personality disorder. Journal of Psychiatric Practice, 15, 449-453. 
Price, K., Gillespie, S., Rutter, D., Dhillon, K., Gibson, S., Faulkner, A., ... Crawford, M. J. (2009). Dedicated personality disorder services: A qualitative analysis of service structure and treatment process. Journal of Mental Health, 18, 467-475.

Project Air Strategy for Personality Disorders (2011). Treatment guidelines for personality disorders. New South Wales: NSW Health and Illawarra Health and Medical Research Institute. Retrieved from www.projectairstrategy.org

Stoffers, J. M., Völlm, B. A., Rücker, G., Timmer, A., Huband, N., \& Lieb, K. (2012). Psychological therapies for people with borderline personality disorder. Cochrane Database of Systematic Reviews, 8(CD005652).

The Quality Assurance Project (1990). Treatment outlines for paranoid, schizotypal and schizoid personality disorders. Australian and New Zealand Journal of Psychiatry, 24, 339-350.

The Quality Assurance Project (1991a). Treatment outlines for borderline, narcissistic and histrionic personality disorders. Australian and New Zealand Journal of Psychiatry, 25, 392-403.

The Quality Assurance Project. (1991b). Treatment outlines for antisocial personality disorder. Australian and New Zealand Journal of Psychiatry, 25, 541-547.

Zanarini, M. C. (2009). Psychotherapy of borderline personality disorder. Acta Psychiatrica Scandinavica, 120, 373-377. 
Table 1. Demographic details of mental health clinicians surveyed

\begin{tabular}{|c|c|c|c|c|}
\hline & $\mathbf{N}$ & $\mathbf{M}$ & SD & Range \\
\hline Age & 60 & 43.66 & 10.61 & $26-65$ \\
\hline Years qualified in occupation & 60 & 12.20 & 7.93 & $2.5-38$ \\
\hline \multirow{2}{*}{$\begin{array}{l}\text { Years of experience in } \\
\text { working with personality } \\
\text { disorders }\end{array}$} & 60 & 8.93 & 6.26 & $2.5-30$ \\
\hline & \multicolumn{2}{|l|}{ Response categories } & $\mathbf{n}$ & $\%$ \\
\hline \multirow[t]{2}{*}{ Gender $(\mathrm{N}=60)$} & Male & & 14 & $23.3 \%$ \\
\hline & Female & & 46 & $76.7 \%$ \\
\hline \multirow[t]{2}{*}{ Place of Birth $(\mathrm{N}=60)$} & Australia & & 45 & $75.0 \%$ \\
\hline & Other & & 15 & $25.0 \%$ \\
\hline \multirow[t]{2}{*}{ First language $(\mathrm{N}=60)$} & English & & 50 & $83.3 \%$ \\
\hline & Other & & 10 & $16.7 \%$ \\
\hline \multirow[t]{2}{*}{ Current Employment $(\mathrm{N}=60)$} & Full-time & & 43 & $71.7 \%$ \\
\hline & Part-time & & 17 & $28.3 \%$ \\
\hline \multirow[t]{6}{*}{ Occupation $(\mathrm{N}=60)$} & Psychiatrist & & 3 & $5.0 \%$ \\
\hline & Psychologist & & 22 & $36.7 \%$ \\
\hline & Clinical Psychologist & & 25 & $41.7 \%$ \\
\hline & Social Worker & & 8 & $13.3 \%$ \\
\hline & Counsellor & & 1 & $1.7 \%$ \\
\hline & Mental Health Nurse & & 1 & $1.7 \%$ \\
\hline \multirow{3}{*}{$\begin{array}{l}\text { Sector of work } \\
(\mathrm{N}=60)\end{array}$} & Private & & 7 & $11.7 \%$ \\
\hline & Public/NSW Health & & 36 & $60.0 \%$ \\
\hline & Both & & 17 & $28.3 \%$ \\
\hline
\end{tabular}




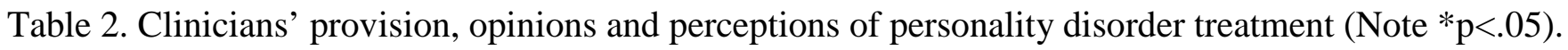

\begin{tabular}{|c|c|c|c|c|c|c|c|c|c|}
\hline \multirow[t]{2}{*}{ Question } & \multicolumn{4}{|l|}{ Response Categories } & Question & \multicolumn{4}{|l|}{ Response Categories } \\
\hline & & $\mathbf{N}$ & $\mathbf{n}$ & $\%$ & & & $\mathbf{N}$ & $\mathbf{n}$ & $\%$ \\
\hline \multicolumn{5}{|l|}{ Treatment provided } & \multicolumn{2}{|c|}{ Perceptions of current level of care } & & & \\
\hline \multirow{7}{*}{$\begin{array}{l}\text { Please identify the } \\
\text { treatment your service } \\
\text { provides for people with } \\
\text { personality disorders }\end{array}$} & Crisis management & $212^{\mathrm{a}}$ & 39 & $18.4 \%$ & Please rate the & Excellent & 58 & 1 & $17 \%$ \\
\hline & Case management & & 33 & $15.6 \%$ & availability of treatment & Good & & 3 & $5.2 \%$ \\
\hline & Dialectical Behaviour Therapy & & 52 & $24.5 \%$ & for people with & Fair & & 32 & $55.2 \%$ \\
\hline & Cognitive Behaviour Therapy & & 35 & $16.5 \%$ & personality disorders & Poor & & 22 & $37.9 \%$ \\
\hline & Psychodynamic therapy & & 18 & $8.5 \%$ & & & & & \\
\hline & Supportive psychotherapy & & 35 & $16.5 \%$ & Please identify the most & Lack of resources & 51 & 26 & $51.0 \%$ \\
\hline & Individual & 60 & 20 & $33.3 \%$ & $\begin{array}{l}\text { significant barrier to } \\
\text { treatment for people }\end{array}$ & $\begin{array}{l}\text { Lack of clinician confidence treating } \\
\text { personality disorder }\end{array}$ & & 5 & $9.8 \%$ \\
\hline \multirow{2}{*}{$\begin{array}{l}\text { What format of treatment } \\
\text { do you provide for people } \\
\text { with personality disorders? }\end{array}$} & Group & & 2 & $3.3 \%$ & with personality & Stigma regarding personality disorders & & 13 & $25.5 \%$ \\
\hline & Combined group \& individual & & 38 & $63.3 \%$ & disorders & Lack of education or support for clinicians & & 7 & $13.7 \%$ \\
\hline \multirow{4}{*}{$\begin{array}{l}\text { What is the typical length of } \\
\text { the treatment for people } \\
\text { with personality disorders } \\
\text { that you provide? }\end{array}$} & Brief (1-10 sessions) & 60 & 3 & $5.0 \%$ & Please rate the level of & Very confident & 57 & 10 & $17.5 \%$ \\
\hline & Short-term (11-40 sessions) & & 8 & $13.3 \%$ & confidence you have & Quite confident & & 24 & $42.1 \%$ \\
\hline & Long-term (more than 40 sessions) & & 26 & $43.3 \%$ & with regard to treating & Somewhat confident & & 22 & $38.6 \%$ \\
\hline & Varies (depends on particular client/ presentation) & & 23 & $38.3 \%$ & $\begin{array}{l}\text { people with personality } \\
\text { disorders }\end{array}$ & Not at all confident & & 1 & $1.8 \%$ \\
\hline \multicolumn{10}{|c|}{ Opinion regarding optimal treatment } \\
\hline \multirow{6}{*}{$\begin{array}{l}\text { What type of treatment do } \\
\text { you think is the optimal } \\
\text { treatment for people with } \\
\text { personality disorders? }\end{array}$} & Crisis management & 51 & 3 & $5.9 \%$ & Do you believe that & Yes & 60 & 58 & $96.7 \%$ \\
\hline & Case management & & 4 & $7.8 \%$ & treatment of people with & No & & 2 & $3.3 \%$ \\
\hline & DBT & & 33 & $64.7 \%$ & personality disorders & & & & \\
\hline & CBT & & 0 & $0.0 \%$ & should be a high & & & & \\
\hline & Psychodynamic therapy & & 9 & $17.6 \%$ & priority within the & & & & \\
\hline & Supportive psychotherapy & & 2 & $3.9 \%$ & health system? & & & & \\
\hline \multirow{5}{*}{$\begin{array}{l}\text { What format of treatment } \\
\text { do you believe is optimal } \\
\text { for treating people with } \\
\text { personality disorders? }\end{array}$} & Combined group \& individual & 55 & 50 & $90.9 \%$ & Is there a need for more & Yes & 60 & 59 & $98.3 \%$ \\
\hline & Group & & 0 & $0.0 \%$ & training on the & No & & 1 & $1.7 \%$ \\
\hline & Individual & & 4 & $7.3 \%$ & treatment of people with & & & & \\
\hline & Either group or individual & & 1 & $1.8 \%$ & personality disorders? & & & & \\
\hline & Not sure & & 0 & $0.0 \%$ & & & & & \\
\hline \multirow{5}{*}{$\begin{array}{l}\text { What do you believe is the } \\
\text { optimal treatment length for } \\
\text { treatment of people with } \\
\text { personality disorders? }\end{array}$} & Brief (1-10 sessions) & 58 & 0 & $0.0 \%$ & Would you be willing to & Yes & 57 & 56 & $98.2 \%$ \\
\hline & Short-term (11-40 sessions) & & 4 & $6.9 \%$ & participate in training & No & & 1 & $1.8 \%$ \\
\hline & Long-term (more than 40 sessions) & & 36 & $62.1 \%$ & workshops on the & & & & \\
\hline & Varies (depends on particular client/ presentation) & & 18 & $31.0 \%$ & treatment of people with & & & & \\
\hline & Not sure & & 0 & $0.0 \%$ & personality disorders? & & & & \\
\hline
\end{tabular}


Table 3. Comparison of Treatment provided by clinicians to what they believe is optimal for treatment of personality disorders (Note ${ }^{*} \mathrm{p}<.05$ ).

\begin{tabular}{|c|c|c|c|c|c|c|c|c|}
\hline & $\mathbf{N}$ & $\mathbf{n}$ & $\begin{array}{r}\% \\
\text { Clinicians } \\
\text { Providing }\end{array}$ & $\mathbf{N}$ & n & $\begin{array}{r}\% \\
\text { Clinicians } \\
\text { who believe } \\
\text { optimal } \\
\end{array}$ & $\mathbf{z}$ & $\mathbf{p}$ \\
\hline Treatment Type & 60 & & & 51 & & & & \\
\hline Crisis management & & 39 & $65.0 \%$ & & 3 & $5.9 \%$ & 6.40 & $.000^{*}$ \\
\hline Case management & & 33 & $55.0 \%$ & & 4 & $7.8 \%$ & 5.25 & $.000^{*}$ \\
\hline Dialectical Behaviour Therapy & & 52 & $86.7 \%$ & & 33 & $64.7 \%$ & 2.72 & $.007 *$ \\
\hline Cognitive Behaviour Therapy & & 35 & $58.3 \%$ & & 0 & $0.0 \%$ & 6.59 & $.000^{*}$ \\
\hline Psychodynamic therapy & & 18 & $30.3 \%$ & & 9 & $17.6 \%$ & 1.51 & .130 \\
\hline Supportive psychotherapy & & 35 & $58.4 \%$ & & 2 & $3.9 \%$ & 6.60 & $.000^{*}$ \\
\hline Treatment Format & 60 & & & 54 & & & & \\
\hline Individual & & 20 & $33.3 \%$ & & 4 & $7.3 \%$ & 3.44 & $.001^{*}$ \\
\hline Group & & 2 & $3.3 \%$ & & 0 & $0.0 \%$ & 1.35 & .176 \\
\hline Combined group \& individual & & 38 & $63.3 \%$ & & 50 & $90.9 \%$ & -3.72 & $.000^{*}$ \\
\hline Treatment Length & 60 & & & 58 & & & & \\
\hline Brief (1-10 sessions) & & 3 & $5.0 \%$ & & 0 & $0.0 \%$ & 1.73 & .084 \\
\hline Short-term (11-40 sessions) & & 8 & $13.3 \%$ & & 4 & $6.9 \%$ & 1.16 & .247 \\
\hline Long-term (more than 40 sessions) & & 26 & $43.3 \%$ & & 36 & $62.1 \%$ & -2.04 & $.042^{*}$ \\
\hline $\begin{array}{l}\text { Varies (depends on particular client/ } \\
\text { presentation) }\end{array}$ & & 23 & $38.3 \%$ & & 18 & $31.0 \%$ & 0.83 & .405 \\
\hline
\end{tabular}

